\title{
Human drug efflux transporter $A B C C 5$ confers acquired resistance to pemetrexed in breast cancer
}

Jihui Chen ${ }^{1 \dagger}$, Zhipeng Wang ${ }^{2 \dagger}$, Shouhong Gao ${ }^{2}$, Kejin Wu${ }^{3}$, Fang Bai ${ }^{3}$, Qiqiang Zhang ${ }^{1}$, Hongyu Wang ${ }^{1}$, Qin Ye ${ }^{1}$, Fengjing $\mathrm{Xu}^{2}$, Hong Sun ${ }^{4}$, Yunshu Lư ${ }^{3^{*}}$ and Yan Liu ${ }^{1 *}$ (D)

\begin{abstract}
Aim: Pemetrexed, a new generation antifolate drug, has been approved for the treatment of locally advanced or metastatic breast cancer. However, factors affecting its efficacy and resistance have not been fully elucidated yet. ATP-binding cassette (ABC) transporters are predictors of prognosis as well as of adverse effects of several xenobiotics. This study was designed to explore whether $A B C$ transporters affect pemetrexed resistance and can contribute to the optimization of breast cancer treatment regimen.
\end{abstract}

Methods: First, we measured the expression levels of $A B C$ transporter family members in cell lines. Subsequently, we assessed the potential role of $A B C$ transporters in conferring resistance to pemetrexed in primary breast cancer cells isolated from 34 breast cancer patients and the role of ABCC5 in mediating pemetrexed transport and apoptotic pathways in MCF-7 cells. Finally, the influence of ABCC5 expression on the therapeutic effect of pemetrexed was evaluated in an in vivo xenograft mouse model of breast cancer.

Results: The expression levels of $A B C C 2, A B C C 4, A B C C 5$, and $A B C G 2$ significantly increased in the pan-resistant cell line, and the ABCC5 level in the MCF-7-ADR cell line was 5.21 times higher than that in the control group. ABCC5 expression was inversely correlated with pemetrexed sensitivity $\left(I_{50}, r=0.741 ; p<0.001\right)$ in breast cancer cells derived from 34 patients. Furthermore, we found that the expression level of ABCC5 influenced the efflux and cytotoxicity of pemetrexed in MCF-7 cells, with $\mathrm{IC}_{50}$ values of 0.06 and $0.20 \mu \mathrm{g} / \mathrm{mL}$ in ABCC5 knockout and over-expression cells, respectively. In the in vivo study, we observed that ABCC5 affected the sensitivity of pemetrexed in breast tumor-bearing mice, and the tumor volume was much larger in the $A B C C 5$-overexpressing group than in the control group when compared with their own initial volumes (2.7-fold vs. 1.3-fold).

Conclusions: Our results indicated that ABCC 5 expression was associated with pemetrexed resistance in vitro and in vivo, and it may serve as a target or biomarker for the optimization of pemetrexed regimen in breast cancer treatment.

\footnotetext{
*Correspondence: liuyan03@xinhuamed.com.cn; Luyunshu@xinhuamed.

com.cn

${ }^{\dagger}$ Jihui Chen and Zhipeng Wang contributed equally to this work

${ }^{1}$ Department of Pharmacy, Xin Hua Hospital, Shanghai Jiao Tong

University School of Medicine, 1665 Kongjiang Road, Shanghai 200092,

China

${ }^{3}$ Department of Breast Surgery, Obstetrics and Gynecology Hospital,

Fudan University, Shanghai 200011, China

Full list of author information is available at the end of the article
}

(C) The Author(s) 2021, corrected publication 2021. This article is licensed under a Creative Commons Attribution 4.0 International License, which permits use, sharing, adaptation, distribution and reproduction in any medium or format, as long as you give appropriate credit to the original author(s) and the source, provide a link to the Creative Commons licence, and indicate if changes were made. The images or other third party material in this article are included in the article's Creative Commons licence, unless indicated otherwise in a credit line to the material. If material is not included in the article's Creative Commons licence and your intended use is not permitted by statutory regulation or exceeds the permitted use, you will need to obtain permission directly from the copyright holder. To view a copy of this licence, visit http://creativecommons.org/licenses/by/4.0/. The Creative Commons Public Domain Dedication waiver (http://creativeco mmons.org/publicdomain/zero/1.0/) applies to the data made available in this article, unless otherwise stated in a credit line to the data. 
Keywords: ABC transporter, Breast cancer, Pemetrexed, Drug resistance, Sensitivity

\section{Introduction}

Pemetrexed (MTA), a novel multitargeted antifolate, is used for the treatment of non-small cell lung cancer and mesothelioma [1-4], and functions by inhibiting thymidylate synthase, dihydrofolate reductase, glycinamide ribonucleotide formyltransferase, and 5-aminoimidazole-4-carboxamide ribonucleotide formyltransferase, which are folate-dependent enzymes involved in the de novo biosynthesis of thymidine and purine nucleotides $[5,6]$. MTA exhibits a good effect (overall response rate: $8 \%$, stable disease state: $36 \%$, median survival: 8 months) in metastatic breast cancer (BC) patients, and is welltolerated in $80 \%$ of the patients receiving second-line treatment [7]. Additionally, in advanced $\mathrm{BC}$ patients, a $30 \%$ response rate is observed when MTA is administered as first-line treatment, whereas a $21 \%$ response rate is observed when MTA is administered as second-line treatment [8].

The mechanism of sensitivity and/or acquired resistance of MTA is complex, mainly including a decreased intracellular concentration and alteration of metabolism, among others [9]. The cytotoxicity of MTA is largely attributed to its concentration and retention time in cells [10]. Thus, the transmembrane transport of MTA is a critical determinant of its activity. In this context, a decreased expression of influx transporters and increased expression of efflux transporters can induce cancer cell resistance by reducing intracellular drug exposure [11, 12]. The ATP-binding cassette $(\mathrm{ABC})$ transporter, also known as multidrug resistance protein [13], is capable of conferring resistance to nucleotide analogs such as fluorouracil (5-FU) [14, 15], 6-thioguanine (6-TG) [16], 6-mercaptopurine (6-MP) [17], and 9-(2-phosphonylmethoxynyl)adenine [18, 19]. The expression of $A B C$ transporters involved in the efflux of endogenous and exogenous substrates is regulated by pregnane $\mathrm{X}$ receptor, constitutive androstane receptor, and other transcriptional regulators [20]. ABC transporters comprise approximately 50 members, which are subdivided into seven groups (ABCA to $A B C G$ ) [21]. In particular, the $C$ branch of $A B C$ transporter superfamily dominates multidrug resistance $[22,23]$. The first study on hydrophilic antifolate transport by certain members of the $A B C C$ family reports that MTA transports into bile in wild-type rats but not in rats with a hereditary deficiency of ABCC2 functions [24]. Subsequently, many studies have reported the effects of $A B C C$ on antifolate transport [25-28]. An absence of $A B C C 2$ and/or ABCG2 in mice increases the oral availability of methotrexate [29]. Another important exporter, $\mathrm{ABCC}$, is reported to be involved in the transport of MTA and folic acid in HEK293 cells [30].

Previous studies have shown that the expression of $A B C$ transporters in human cancer can influence the efficacy of chemotherapy. However, the contribution of $\mathrm{ABC}$ transporters to drug resistance, especially to novel antifolate drugs, has not been fully elucidated. Therefore, this study was conducted to explore the influence of $A B C$ transporters on MTA sensitivity and resistance in BC.

\section{Materials and methods \\ Cell lines}

Breast cancer cell lines, MCF-7 and MCF-7-adriamycinresistant cells (MCF-7-ADR), were obtained from the Culture Collection Company (ATCC-LGC Promochem, Teddington, UK). Cells were routinely grown in Dulbecco's modified eagle's medium (DMEM, Invitrogen, Carlsbad) supplemented with $10 \%$ fetal bovine serum (FBS, Invitrogen) and 100 units of penicillin/streptomycin per $\mathrm{mL}$ (Invitrogen) at $37^{\circ} \mathrm{C}$, and they were kept in a humidified environment under $5 \% \mathrm{CO}_{2}$. The medium was replaced regularly every $2-3$ days until the cells reached $80-90 \%$ confluence. Following this, the cells were transferred to perform experiments or make stock solutions. Mycoplasma contamination was tested every month.

\section{Reagents}

MTA (reference substance solution), which was used for quantitative analysis in a reverse phase-high performance liquid chromatography (RP-HPLC) experiment, was purchased from Sigma-Aldrich (St. Louis, MO, USA). MTA used for cell incubation was purchased from Eli Lilly Company (Indianapolis,USA). ABCC5 human shRNA was purchased from OriGene (Locus ID: 10,057, Product ID: TL315024, Rockwell, USA). Rabbit anti-human antiMRP5 antibody [M5II-54, ab137070, Abcam, Cambridge, UK), rabbit anti-human Bax mAb (5023, Cell Signaling Technology, Boston, USA), rabbit anti-human caspase-3 mAb (14,220, Cell Signaling Technology), cleaved caspase-3 mAb (9664, Cell Signaling Technology, Boston, USA), and $\beta$-actin (13E5) rabbit mAb (4970, Cell Signaling Technology, Boston, USA) were used as primary antibodies, and goat anti-rabbit IgG (final dilution 1:2000; LI-COR Biosciences, Lincoln, NE, USA) was used as a secondary antibody.

\section{Construction of $A B C C 5$ adenovirus}

For recombinant adenovirus construction, ABCC5 cDNA (AdvABCC5) and green fluorescent protein cDNA 
(AdvCtrl, control) were cloned using PCR, and were inserted into the pHBAD-EF1-MCS-3flag-CMV-EGFP vector (Additional file 1: Fig. S1). pDC315-ABCC5 and pBHGloxE1,3Cre were co-transfected into HEK293 cells (ATCC, Manassas, USA) using the LipoFiterTM transfection reagent (QIAGEN, Dusseldorf, Germany) to generate recombinant adenoviruses. The recombinant adenoviruses, AdvABCC5 and AdvCtrl, produced in HEK293 cells were purified, and viral titer was measured using a plaque assay. The stock solutions of both AdvABCC5 and AdvCtrl contained $1 \times 10^{11}$ plaque formation unit (PFU)/ $\mathrm{mL}$.

\section{Collection of tumor tissue specimens and isolation of primary $B C$ cells}

A total of 34 patients with confirmed primary BC $(2 \mathrm{~cm}$ or larger), who consecutively underwent neoadjuvant chemotherapy with anthracyclines at the Breast Tumor Department, Xin Hua Hospital, Shanghai Jiao Tong University School of Medicine, were enrolled in the study from January 2014 to December 2015. Tumor specimens were surgically excised prior to MTA chemotherapy. Informed consent was obtained from all patients, following a protocol approved by the Ethics Committee of Xin Hua Hospital, Shanghai Jiao Tong University School of Medicine.

To isolate BC cells, at least two consecutive frozen sections were prepared for each paraffin-embedded tumor tissue sample, and one of the sections was subjected to hematoxylin-eosin staining to confirm the presence of cancer cells. The adjacent sections were transferred for cancer cell isolation, as previously described [30]. Briefly, the blood, and fat and fibro connective tissue were removed from tumor tissue samples. Subsequently, the residual section was cut into 1-2 mm pieces for enzymatic disaggregation. The small tissue pieces were incubated with $2.5 \%$ crude trypsin (QIAGEN, Dusseldorf, Germany) for $30 \mathrm{~min}$ at $37{ }^{\circ} \mathrm{C}$ and $0.15 \%$ collagenase (QIAGEN, Dusseldorf, Germany) overnight. Cells released after enzymatic treatments were further tested for cell viability, and they were cultured to perform subsequent experiments.

\section{Animal studies}

Twenty-four female BALB/c nude mice (5 weeks, $18 \mathrm{~g}$ ) were purchased from the Shanghai Super B\&K Laboratory Animal Corp. Ltd. (Shanghai, China), and they were raised in a specific pathogen-free environment with free access to food and water. All animal studies were approved by the Research Ethics Committee of Xin Hua Hospital, affiliated to the Shanghai Jiao Tong University School of Medicine.
On Day $0,1 \times 10^{7}$ MCF-7 cells were subcutaneously injected into the right armpits of mice. After the development of tumors to approximately $100 \mathrm{~mm}^{3}$ on Day 30, adenoviruses containing ABCC5 (AdvABCC5, $5 \times 10^{11}$ $\mathrm{PFU})$ were injected into the tumors of 12 mice to overexpress $\mathrm{ABCC} 5$ in tumor cells, and the vehicle AdvCtrl was applied to the other 12 control mice. The expression of $\mathrm{ABCC} 5$ was checked using diffuse green fluorescence. When the volume of tumors was approximately 150 $\mathrm{mm}^{3}$ on Day 35, six of the ABCC5-overexpressing mice and six control mice were intravenously injected (via the tail vein) with MTA (20 mg/ $\mathrm{kg}$, saline) once a day, and the same dose of vehicle was administered to the others from Day 35 to 46 . The tumor volumes $(\mathrm{V})$ were measured using a caliper once a day $\left(\mathrm{V}=\right.$ width $^{2} \times$ length/2). Mice were killed at the end of seventh week, and tumor volume and weight were measured. The design of animal experiments is shown in Fig. 1.

\section{Determination of MTA in MCF-7 cells using RP-HPLC}

MTA concentrations in MCF-7 cells were determined based on a developed HPLC method. Chromatographic separation and quantification were performed using an RP column (ZORBAX Eclipse XDB-C8, $250 \mathrm{~mm} \times 4.6 \mathrm{~mm}, 5 \mu \mathrm{m}$; Agilent, Santa Clara, USA) with the column temperature maintained at $25^{\circ} \mathrm{C}$. MTA was detected using an ultraviolet detector (Agilent 1260 HPLC, Agilent, Santa Clara, USA) at a wavelength of $240 \mathrm{~nm}$. The mobile phase was composed of water and $0.02 \mathrm{M}$ phosphate buffer ( $\mathrm{pH} 4.0)$ /acetonitrile (86:14, $\mathrm{V}: \mathrm{V})$, and it was delivered at a flow rate of $1 \mathrm{~mL} / \mathrm{min}$. Sample pretreatment was completed using ultrafiltration $(0.22 \mu \mathrm{m})$. All experiments were performed using an Agilent 1260 HPLC system. A calibration curve was constructed in the range of $80-625 \mathrm{ng} / \mathrm{mL}$ for MTA measurement. The injection volume was $20 \mu \mathrm{L}$, and all experiments were performed in triplicate.

\section{Cell preparation for cellular uptake analysis}

MCF-7 cells were seeded at $2 \times 10^{5} /$ well into six-well flatbottom tissue-culture plates in triplicate. After $24 \mathrm{~h}$, the cells were infected with ABCC5-, Ctrl-, and siABCC5RNA-expressing adenoviruses. The cells were incubated with adenoviral particles for another $24 \mathrm{~h}$; subsequently, they were refreshed with a medium containing $50 \mu \mathrm{M}$ MTA $(21.37 \mu \mathrm{g} / \mathrm{mL})$. At specific time points $(0,0.5,1$, 2,4 , and $24 \mathrm{~h}$ ), the cells were washed three times with cold phosphate buffered saline (PBS, $0.1 \mathrm{M}, \mathrm{pH} 7.4$, Sigma-Aldrich, St. Louis, USA), resuspended in $0.2 \mathrm{~mL}$ RPMI-1640 medium (Sigma-Aldrich, St. Louis, USA), and homogenized. After centrifugation at $13,000 \times \mathrm{g}$ for $10 \mathrm{~min}$, the supernatant was harvested and stored 
MCF-7 cells
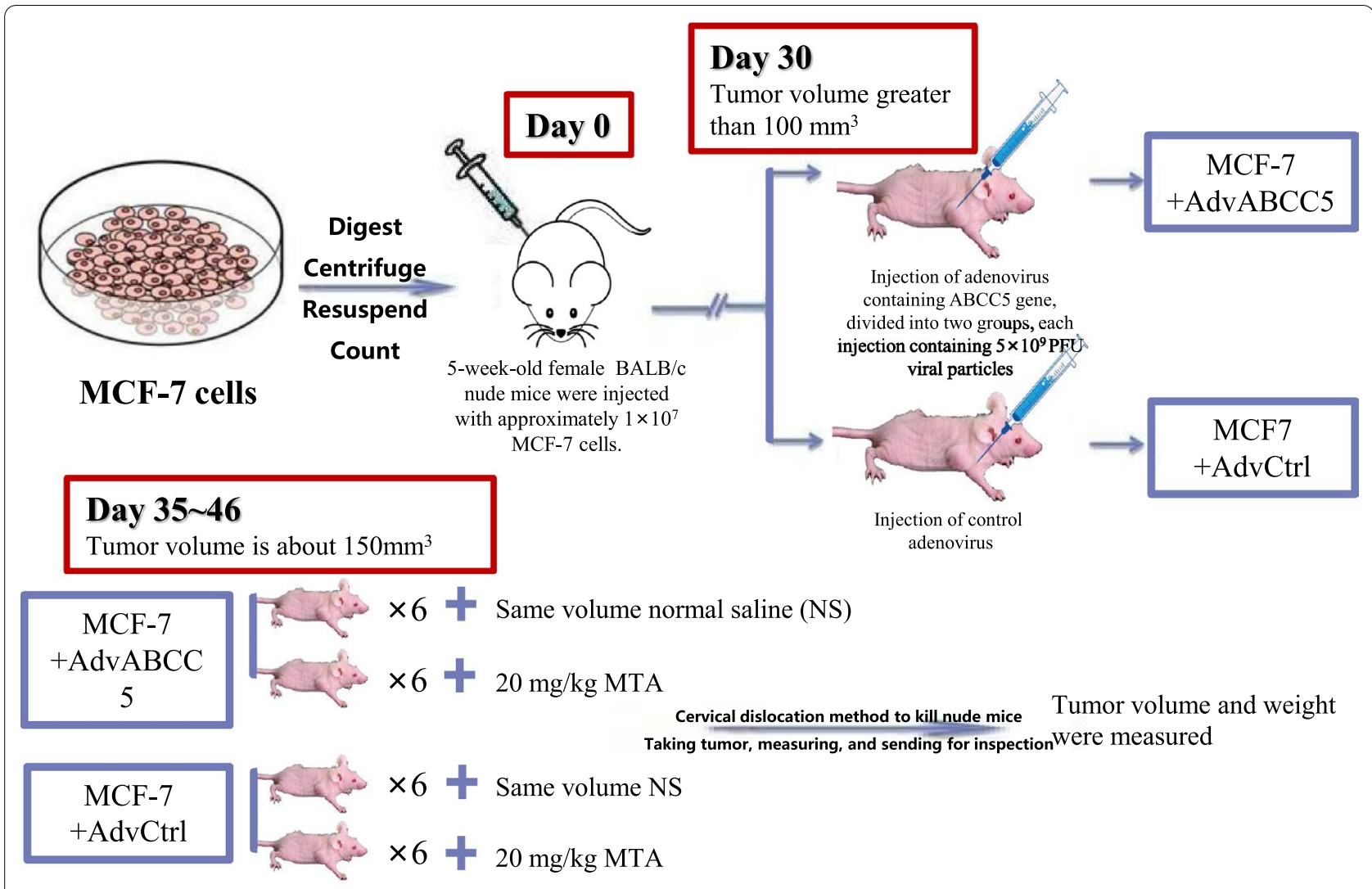

Fig. 1 Schematic diagram of animal study to evaluate the influence of ABCC5 expression on pemetrexed (MTA) efficacy

at $-80{ }^{\circ} \mathrm{C}$ for the detection of MTA using RP-HPLC, as mentioned above.

\section{Cell viability assay}

The cell viability assay was performed using a CCK-8 kit (Dojindo Laboratories, Kumamoto, Japan) according to manufacturer's instructions. Briefly, cells were plated in 96-well plates at a density of 2000 cells/well, and subsequently, they were treated with different concentrations of MTA for $72 \mathrm{~h}$. Following this, CCK- 8 solution diluted with DMEM/F12 and 10\% FBS at a 1:10 ratio was added to each well, and the plate was incubated at $37{ }^{\circ} \mathrm{C}$ for $2 \mathrm{~h}$. Finally, absorbance was measured using a SYNERGY microplate reader (BioTek, Winooski, USA) at $450 \mathrm{~nm}$. The (\%) cell viability was calculated using the following formula: (OD treatment group-OD blank)/(OD control group-OD blank) $\times 100$. $\mathrm{IC}_{50}$ values were determined using the GraphPad Prism software (GraphPad Prism software, Inc. San Diego, USA). All experiments were performed in triplicate, and the presented data represent the mean of three biological repeats.

\section{Western blotting}

Tissues and cells were homogenized in ice-cold $1 \times$ RIPA lysis buffer (Thermo Fisher Scientific, Waltham, USA) containing protease inhibitor cocktail (Roche, Basel, Switzerland), and they were centrifuged at $12,000 \times \mathrm{g}$ for 15 min. Protein extracts were separated using 5 to $12 \%$ SDS-PAGE (Beyotime Biotechnology, Shanghai, China), and subsequently, they were electrophoretically transferred to nitrocellulose membranes (Bio-Rad, R\&D systems, Emeryville, USA). After blocking with 5\% fat-free milk, the membranes were incubated with primary antibodies against ABCC5 (1:500, Cell Signaling Technology), caspase-3 (1:1000, Cell Signaling Technology), Bax (1:1000, Abcam), or $\beta$-actin (1:5000, Proteintech, Rosemont, USA) and subsequently with IRDye 700 or 800 secondary antibodies (1:10,000, LI-COR Biosciences), and they were visualized using the Odyssey Infrared Imaging System software (LI-COR Biosciences).

\section{RNA isolation and quantitative real-time PCR (qRT-PCR)}

Total RNA was extracted from cells using a RNeasy mini kit (QIAGEN), and qRT-PCR was performed on the cDNAs generated from 250 ng total RNA using the 
HotStart-IT ${ }^{\circledR}$ SYBR $^{\circledR}$ Green qPCR Master Mix with UDG (2X) and a user-friendly TM kit (USB Corporation). The expression of each gene was calculated using the $2^{-\Delta \Delta \mathrm{C}_{\mathrm{T}}}$ method with $18 \mathrm{~S}$ rRNA as an internal control. $\mathrm{ABC}$ transporter subfamily primers were designed and synthesized by Sangon Biotech Co., Ltd. (Shanghai, China, Additional file 2: Table S1).

\section{Immunofluorescence microscopy}

Cells were initially seeded onto coverslips, harvested, and washed three times with PBS. Cells were fixed with $4 \%$ paraformaldehyde for $30 \mathrm{~min}$ at room temperature and blocked with $1 \%(\mathrm{w} / \mathrm{v})$ bovine serum albumin, $0.1 \%$ Triton $\mathrm{X}-100$, and $0.05 \%$ Tween- 20 at $4{ }^{\circ} \mathrm{C}$ overnight to avoid nonspecific staining. Next, the cells were incubated overnight with the goat polyclonal antibody, anti-ABCC5. Subsequently, the rabbit anti-goat secondary antibody (TRITC, 1:100) was added, and the cells were incubated in the dark for $1 \mathrm{~h}$. DAPI staining was used to visualize cell nuclei. Images were captured using a Leica DMI300B inverted fluorescent microscope(Leica Microsystems, Weztlar, Gemany).

\section{Data analysis}

The results are presented as mean $\pm \mathrm{SD}$. The graphics and calculations were performed using Microsoft Excel (Microsoft Corp) or Prism 5.0 software. The $\mathrm{IC}_{50}$ values were calculated using nonlinear regression from a sigmoidal dose-response curve (variable slope, bottom value 0) using the Prism software. Pearson's correlation test was used to analyze the correlation between target gene expression and $\mathrm{IC}_{50}$ values. A $p$ value $<0.05$ was considered statistically significant using an unpaired $t$-test unless stated otherwise.

\section{Results}

Expression of $A B C$ transporters increases in the MCF-7-ADR cell line

The expression of the members of the $\mathrm{ABC}$ transporter subfamily was measured using qPCR in resistant MCF-7ADR and control cells (MCF-7), and 18S RNA expression was utilized as an internal standard to normalize data. Almost all $\mathrm{ABC}$ transporters were upregulated in MCF7-ADR cells as compared to that in control cells. The expression levels of $\mathrm{ABCC} 1$ (up to 1.50 times), $\mathrm{ABCC} 2$ (1.46 times), ABCC4 (4.31 times), and ABCC5 (5.21 times) were significantly increased, and among them, the change in $\mathrm{ABCC} 5$ level was most significant, which indicates its critical role in MTA resistance (Additional file 1: Fig. S2).

\section{ABCC5 expression in $B C$ tissues correlates} with MTA-induced cell toxicity

To investigate the correlation between ABCC expression and cellular sensitivity $\left(\mathrm{IC}_{50}\right)$ to MTA in patients, we enrolled $34 \mathrm{BC}$ patients and tested the $\mathrm{IC}_{50}$ of primary $\mathrm{BC}$ cells isolated from tissue samples. Additionally, we performed mRNA expression analysis of 11 ABC transporter family genes in BC cells (Additional file 1: Fig. S3). Pearson's correlation analysis was performed to evaluate the association between $\mathrm{ABCC}$ expression and $\mathrm{BC}$ cell viability. Among the $\mathrm{ABC}$ transporter subfamilies, the expression of $\mathrm{ABCC} 2$ was highest, but no association was observed with MTA sensitivity $(\mathrm{R}=0.07, p=0.71)$. Only ABCC5, as shown in Fig. 2, presented a significant correlation with the $\mathrm{IC}_{50}$ of MTA $(\mathrm{R}=0.741, p<0.001)$. ABCC5 may dominate ABC transporter-mediated MTA resistance in $\mathrm{BC}$.

\section{Effect of ABCC5 on MTA efflux}

To validate the functional significance of ABCC5 in drug efflux, we transduced MCF-7 cells with either AdvABCC5 or AdvCtrl. As shown in Fig. 3a, the transduction of MCF-7 cells with AdvABCC5 resulted in a tenfold increase in $\mathrm{ABCC} 5$ protein expression. Immunofluorescence microscopy revealed that ABCC5 was expressed on the cell membrane, and an obvious increase in ABCC5 expression was observed in the AdvABCC5 group compared to that in the control (AdvCtrol, Fig. 3b). ABCC5 siRNA was used to knockdown ABCC5 expression, and the results revealed that ABCC5 mRNA expression was completely suppressed (Fig. 3c). Next, we investigated whether alterations in ABCC5 expression in MCF-7

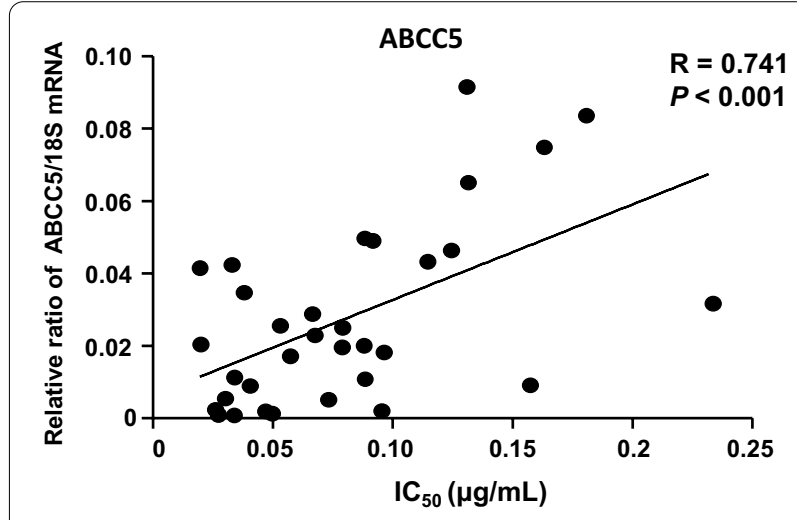

Fig. 2 Correlation between the $I C_{50}$ values of MTA and expression of ABCC5 mRNA in primary cell lines from breast cancer (BC) patients $(r=0.741 ; p<0.001$, Pearson's correlation test). The primary BC cells were cultured with a series of concentrations of MTA for $72 \mathrm{~h}$, and then used to extract RNA for subsequent real-time RT-PCR. The dots represent means of three cell viability assays performed in triplicate, and $18 \mathrm{~S}$ rRNA was used as an endogenous control 


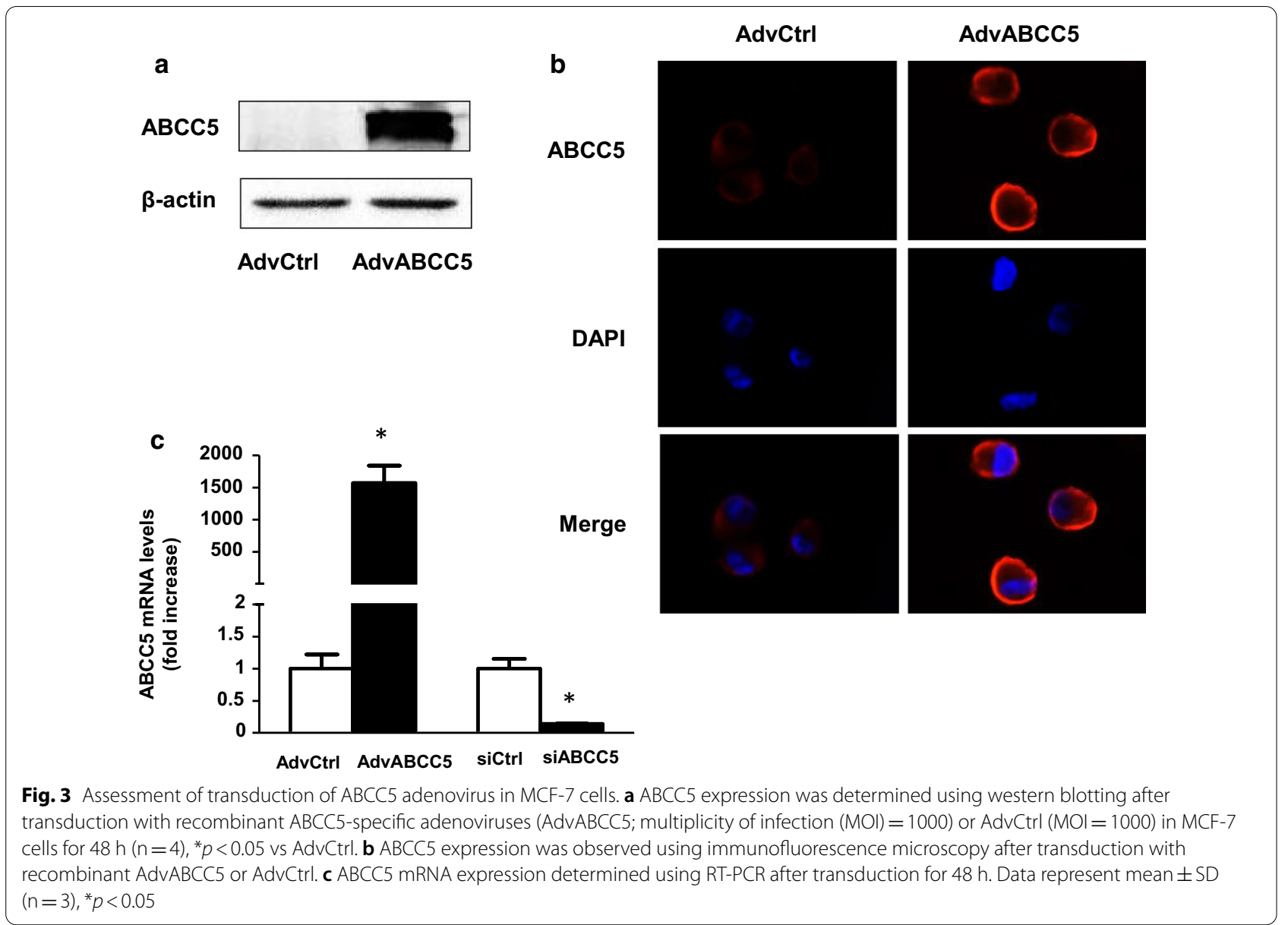

cells could influence the efflux of MTA and thereby alter its intracellular concentration. MCF-7, ABCC5-overexpressing MCF-7, and ABCC5-knockdown MCF-7 cells were treated with $21.37 \mu \mathrm{g} / \mathrm{mL}$ MTA at $37{ }^{\circ} \mathrm{C}$ for $0,0.5,1$, $2,3,4$, or $24 \mathrm{~h}$. Subsequently, the cells were collected and processed to extract intracellular MTA, and the supernatant was analyzed to determine intracellular MTA concentrations. The intracellular MTA concentration was much lower in ABCC5-overexpressing cells and higher in ABCC5-knockdown cells as compared to that in control cells $(p<0.05$, Fig. 4$)$. Our results indicate a negative correlation between $\mathrm{ABCC} 5$ expression and intracellular MTA concentration in MCF-7 cells.

\section{Overexpression of ABCC5 weakens the cytotoxicity of MTA} The cytotoxic effect of MTA was evaluated in ABCC5silenced MCF-7, ABCC5-overexpressing MCF-7, and MCF-7 cells using the CCK- 8 assay. As shown in Fig. $5 \mathrm{a}$, the $\mathrm{IC}_{50}$ of MTA was significantly decreased after $\mathrm{ABCC} 5$ expression was silenced $\left(\mathrm{IC}_{50}=0.06 \pm 0.01\right.$ and $0.11 \pm 0.06 \mu \mathrm{g} / \mathrm{mL}$ for ABCC5-silenced and normal MCF-7 cell lines, respectively, $p=0.02$ ), and the $\mathrm{IC}_{50}$

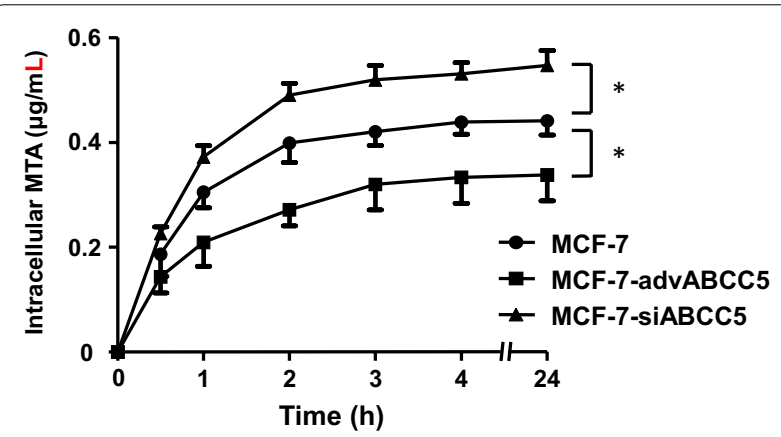

Fig. 4 Intracellular concentration-time curve of MTA influenced by the expression of ABCC5 in MCF-7 cells. Data represent mean \pm SD $(n=3),{ }^{*} p<0.05$. The cells were incubated at $37^{\circ} \mathrm{C}$ with $50 \mu \mathrm{M}$ $(21.37 \mu \mathrm{g} / \mathrm{mL}$ ) MTA for $0,0.5,1,2,3,4$, and $24 \mathrm{~h}$. After washing three times with cold phosphate buffered saline $(0.1 \mathrm{M}, \mathrm{pH} 7.4)$, the cells were resuspended in RPMI-1640 (0.2 mL) and homogenized. MTA was quantified in the supernatant after centrifugation using RP-HPLC

increased to $0.2 \pm 0.05 \mu \mathrm{g} / \mathrm{mL}$ when $\mathrm{ABCC} 5$ expression was upregulated ( $p=0.003$, compared to MCF-7 group). Compared to control cells, an obvious right shift in the 


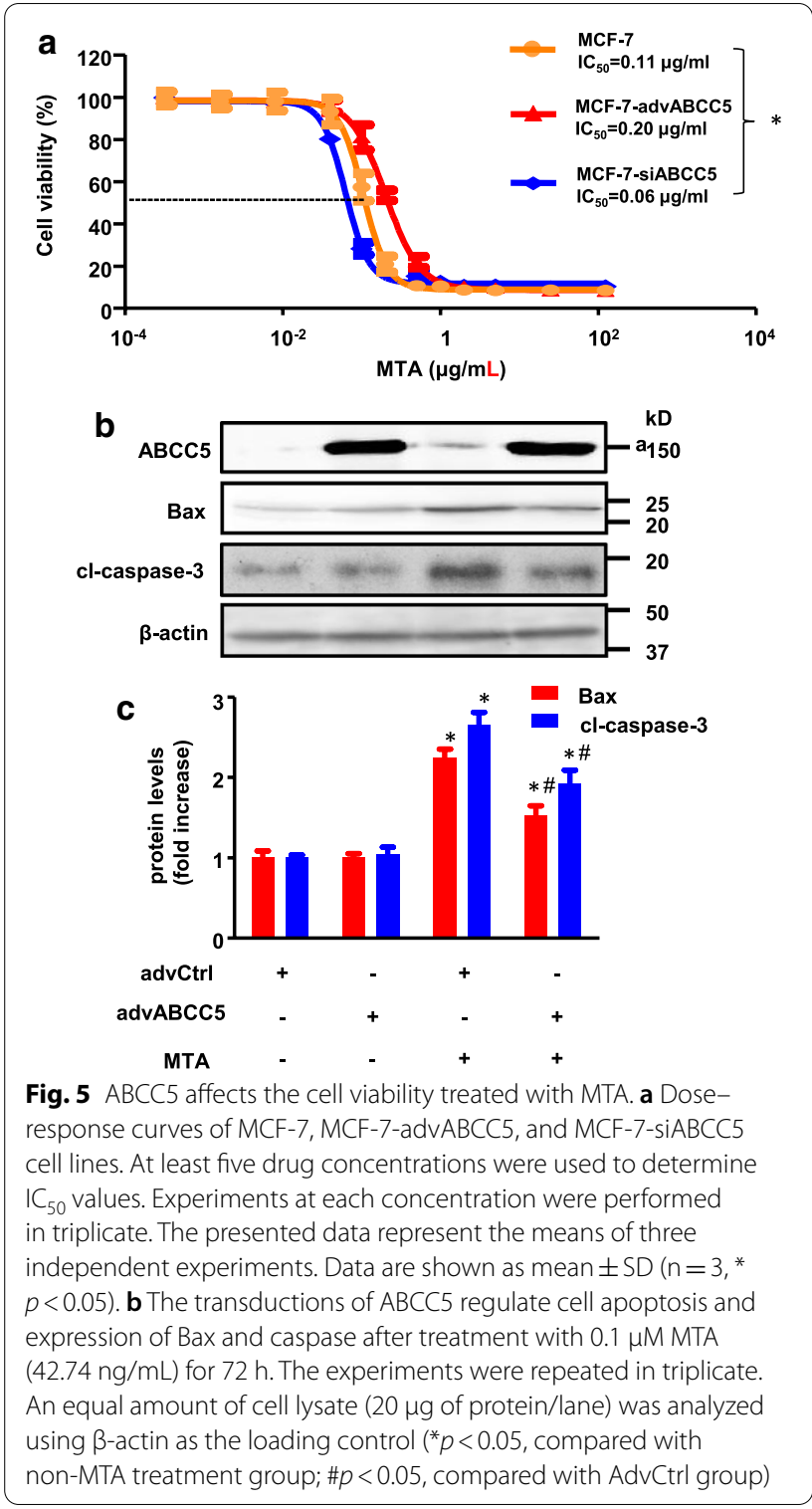

dose-response curve was observed in ABCC5-overexpressing cells, and an inverse shift in the curve was observed in ABCC5-knockdown MCF-7 cells. To further investigate MTA-induced apoptosis, the expression levels of cleaved caspase- 3 and Bax were measured using western blotting. As shown in Fig. 5b, the expression levels of cleaved caspase- 3 and Bax were significantly downregulated $(p<0.05)$ in ABCC5-overexpressing cells, which represents a decline in cell apoptosis.

\section{ABCC5 affects tumor growth in MTA-treated mice}

The therapeutic effects of MTA were evaluated in mice bearing MCF-7 + AdvCtrl or MCF7 + AdvABCC5 tumor xenografts. As shown in Fig. 6a, MTA treatment $(20$ mg/ $\mathrm{kg}$ ) resulted in an average $77.7 \%$ decrease in tumor volume in mice bearing MCF-7 + AdvCtrl tumor xenografts, whereas it led to a $41.3 \%$ decrease in tumor volume in mice bearing MCF7 + AdvABCC5 tumor xenografts. By the end of the experiment, the tumor volume in MTAuntreated mice increased by 4.4-fold than the initial tumor volume $\left(150 \mathrm{~mm}^{3}\right)$. The tumor volume in AdvCtrl MTA-treated mice increased by 1.3-fold. whereas the tumor volume in ABCC5-overexpressing MTA-treated mice increased by 2.7 -fold (untreated AdvCtrl mice: 665 $\mathrm{mm}^{3}$, MTA-treated AdvCtrl mice: $195 \mathrm{~mm}^{3}$, untreated AdvABCC5 mice: $703 \mathrm{~mm}^{3}$, MTA-treated AdvABCC5 mice: $412 \mathrm{~mm}^{3}$; AdvCtrl-MTA group vs. untreated AdvCtrl mice group: $p<0.01$, AdvABCC5-MTA group vs. untreated AdvABCC5 mice group: $p<0.01$ ). Additionally, the tumor size of AdvABCC5 group was significantly higher than that of AdvCtrl group when treated with MTA $(p<0.01)$. These results suggest that ABCC5 overexpression can reduce the cytotoxic effects of MTA in vivo. (Fig. 6b, c).

\section{Discussion}

The expression levels of all multidrug resistant proteins increased in the MCF-7-ADR cell line; in particular, the $\mathrm{ABCC} 5$ gene showed the highest increase in expression. This was further confirmed by ABCC 5 overexpression in MCF-7 cells, wherein the cells showed a reduced sensitivity, decreased accumulation, and enhanced efflux of MTA, which eventually led to the repression of cell apoptosis. Furthermore, the effect of ABCC5 on MTA resistance was confirmed in an in vivo xenograft model.

Chemotherapy is one of the main options for treating nonresectable $\mathrm{BC}$. However, the development of resistance to chemotherapeutic agents has become a critical problem in clinical practice. Multidrug resistance can be influenced by several factors, and the modulation of expression and function of drug resistant proteins contributes towards resistance [31]. ABC transporters are especially critical for the emergence of multidrug resistance in cancer [32]. It has been reported that the expression levels of many proteins, such as P-glycoprotein, $A B C$ transporters, breast cancer resistance protein (ABCG2), lung resistance-related protein [33], ABCB5 [34], and ABCA8 [35], were upregulated during multidrug resistance development in cell lines, which form a unique defense network against several chemotherapeutic drugs and cellular toxins. Many studies have suggested the role of $A B C$ transporters in the efflux of folate and antifolate drugs $[10,35]$. ABCC5 is also involved in the efflux of different anticancer drugs such as 6-MP, 6-TG, 5-FU, and their metabolites [14-19], and this efflux is often associated with drug resistance. Additionally, studies have shown that gene polymorphisms of $\mathrm{ABC}$ transporters 

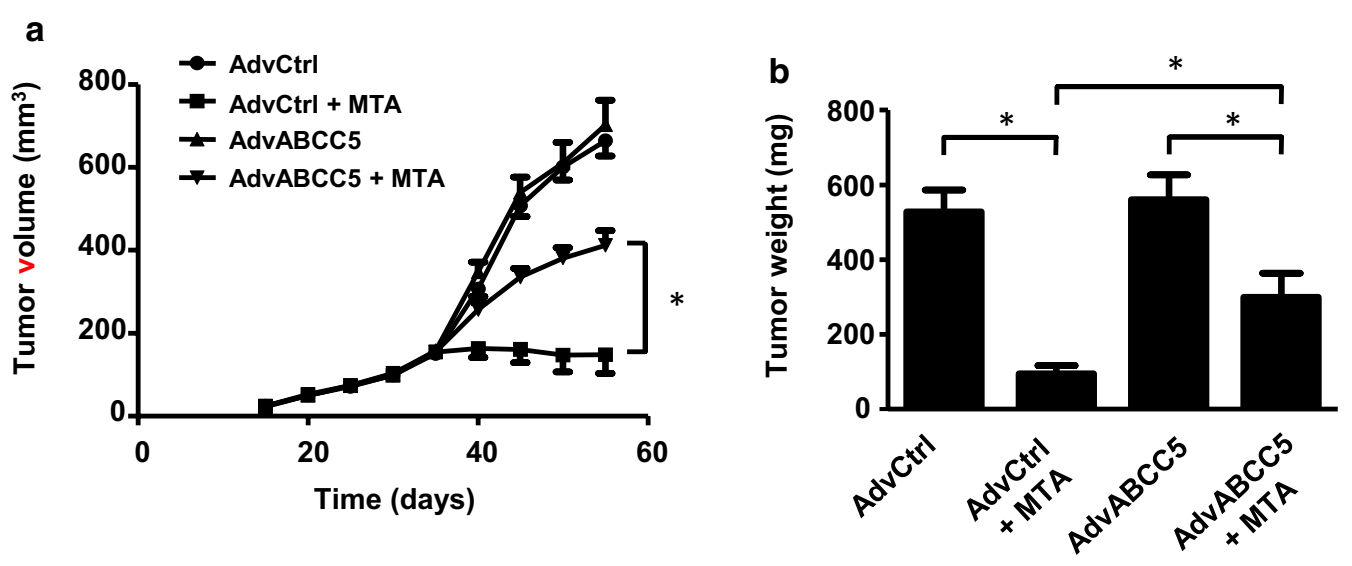

C

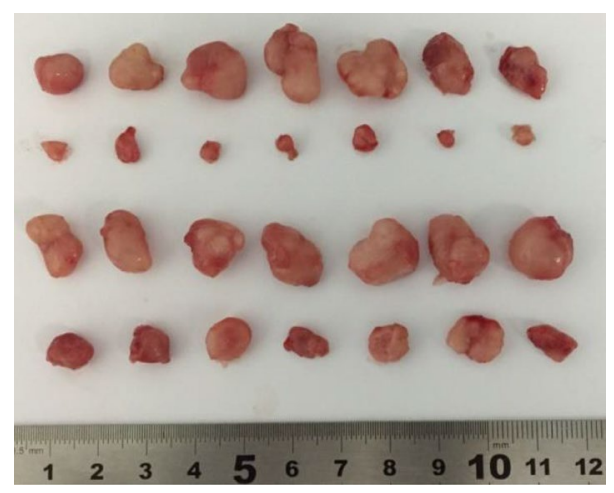

AdvCtrl

AdvCtrl + MTA

AdvABCC5

AdvABCC5 + MTA

Fig. 6 Overexpression of $A B C C 5$ in mice bearing subcutaneous BC xenografts reduces the antitumor activity of MTA. Tumor size was measured with a caliper (a). The excised tumors were weighed at the end point $(\mathbf{b})$, and data are presented as mean $\pm \operatorname{SD}(n=6),{ }^{*} p<0.05$. Images of excised tumors from each group are shown (c)

influence protein expression and determine the efficacy of some anticancer agents [36, 37], despite paradoxical results in some studies.

In our study, we observed that ABCC5 overexpression in MCF-7 cells resulted in an increased resistance to high concentrations of MTA. This can be explained by the increased efflux of MTA from cells via ABCC5, which consequently led to a decrease in MTA accumulation inside the cells, reducing its activity and increasing resistance. In general, it has been observed that upregulated ABCC5 exports nucleoside analogs and increases drug resistance in the range of 2- to tenfold in in vitro assays.

Clinically, the role of $\mathrm{ABC}$ transporters in intrinsic or acquired resistance is not clearly understood. Uemura et al. reported that $\mathrm{ABCC} 11$ directly confers resistance to MTA by enhancing the efflux of intracellular anti-cancer drugs in lung cancer [38], which suggests that $\mathrm{ABCC} 11$ may be a biomarker for MTA in the treatment of lung cancer. Oguri et al. observed that paclitaxel could induce the expression of $\mathrm{ABCC} 10$ gene, which then increases paclitaxel resistance by enhancing paclitaxel efflux [39]. In nasopharyngeal carcinoma cells, paclitaxel induces ABCC5 expression through the activation of FOXM1, and its blockage resensitizes the cells to paclitaxel [40]. A study has shown that ABCC5 expression is significantly associated with the sensitivities of a panel of non-small-cell lung cancer cell lines to gemcitabine, and inhibition of transporter activity by small molecule inhibitors or siRNA knockdown can significantly resensitize cancer cells to gemcitabine [41]. Moreover, in BC, ABCC5 is significantly overexpressed in the non-responding group after neoadjuvant chemotherapy than in the responding group [42]. Nambaru PK et al. reported that when $\mathrm{ABCC} 5$ is upregulated in colorectal cancer and $\mathrm{BC}$, the monophosphorylated metabolite of 5-FU effluxes via $\mathrm{ABCC}$, which contributes to 5-FU resistance [10]. Other studies have reported that ABCC5 is expressed and functionally active in pancreatic adenocarcinoma cell lines, and it contributes to drug sensitivities [10, 11]. Our study observed a close relationship between ABCC5 expression and cellular sensitivity to MTA in $B C$ cells $(R=0.741)$, and this phenomenon was accompanied by a significantly decreased accumulation and 
enhanced efflux of MTA in ABCC5-overexpressing cell lines. In general, a comprehensive profiling of $A B C$ transporters was conducted, which suggested that $A B C$ transporters may serve as promising targets to drastically improve outcomes in cancer treatment.

\section{Conclusion}

Our results showed that the upregulated $A B C$ transporter, $\mathrm{ABCC} 5$, was positively correlated with MTA resistance in $B C$ due to an increased efflux of MTA. Thus, ABC transporters may be a new target for anticancer treatment. Further studies are required to quantitatively assess the relationship between $\mathrm{ABCC} 5$ expression and MTA dosage in order to evaluate ABCC5 expression level as a biomarker for dose optimization of MTA or new target for BC treatment.

\section{Abbreviations}

MTA: Pemetrexed; BC: Breast cancer; ABC transporter: ATP-binding cassette transporter; ABCC5: ATP-binding cassette, sub-family C, member 5; RP-HPLC: Reversed phase high performance liquid chromatography; 5-FU: 5-Fluorouracil; 6-TG: 6-Thioguanine; 6-MP: 6-Mercaptopurine; PFU: Plaque formation unit; DMEM: Dulbecco's modified eagle's medium; PBS: Phosphate buffered saline; FBS: Fetal bovine serum.

\section{Supplementary Information}

The online version contains supplementary material available at https://doi. org/10.1186/s12935-021-01842-X.

Additional file 1: Fig. S1. ABCC5 adenovirus map. Fig. S2. Expression of ABC transporters mRNA in MCF-7 and MCF-7ADR cell lines The a-tubulin was used for normalizing of CDNA sample. Results are given as mean \pm SD from three separate experiments ${ }^{*} p<0.05$. Fig. S3. Correlation of $I C_{50}$ values of MTA and mRNA expression of ABCC transporters in primary cell lines from patients.

Additional file 2: Table S1. The forward and reverse premiers of ABCC transporter sub-family.

\section{Acknowledgements}

This work was supported by the National Institute of Chinese Natural Science Foundation grants 81202598 (Y.L), 81702588 (Y.S.L), 81403021(H.S), 12JC1406800 (K.J.W), and 14411950206 (K.J.W); Shanghai Municipal Bureau of Health Grant 20ZR1435400 (Y.L); and Shanghai Collaborative Innovation Center for Translational Medicine grant TM201710 (Y.L).

\section{Authors' contributions}

JC and ZW wrote the manuscript and performed most experiments. SG, KW, FB, QZ, HW, QY, FX, and HS executed the experiments and analyzed data. YL and $Y L$ reviewed and edited the manuscript and supervised and administered the project. All authors read and approved the final manuscript.

\section{Availability of data and materials}

All data and materials are included in the paper.

\section{Ethical approval and consent to participate}

Informed consent was obtained from all patients, and all experiments were approved by the Research Ethics Committee of Xin Hua Hospital affiliated to Shanghai Jiao Tong University School of Medicine.

\section{Consent for publication}

All authors have reviewed and approved this manuscript.

\section{Competing interests}

The authors declare no conflict of interest regarding the content of the article.

\section{Author details}

${ }^{1}$ Department of Pharmacy, Xin Hua Hospital, Shanghai Jiao Tong University School of Medicine, 1665 Kongjiang Road, Shanghai 200092, China. ${ }^{2}$ Department of Pharmacy, Changzheng Hospital, Second Military Medical University, Shanghai 200003, China. ${ }^{3}$ Department of Breast Surgery, Obstetrics and Gynecology Hospital, Fudan University, Shanghai 200011, China. ${ }^{4}$ Department of Pharmacy, Provincial Clinical College of Fujian Medical University, Fujian Provincial Hospital, Fuzhou 350001, China.

Received: 2 November 2020 Accepted: 17 February 2021

Published online: 25 February 2021

\section{References}

1. Langer CJ, et al. Carboplatin and pemetrexed with or without pembrolizumab for advanced, non-squamous non-small-cell lung cancer: a randomised, phase 2 cohort of the open-label KEYNOTE-021 study. Lancet Oncol. 2016;17(11):1497-508.

2. Senan S, et al. PROCLAIM: randomized phase III trial of pemetrexedcisplatin or etoposide-cisplatin plus thoracic radiation therapy followed by consolidation chemotherapy in locally advanced nonsquamous nonsmall-cell lung cancer. J Clin Oncol. 2016;34(9):953-62.

3. Zhao M, et al. DHFR/TYMS are positive regulators of glioma cell growth and modulate chemo-sensitivity to temozolomide. Eur J Pharmacol. 2019;863:172665

4. Kuo WT, et al. High pemetrexed sensitivity of docetaxel-resistant A549 cells is mediated by TP53 status and downregulated thymidylate synthase. Oncol Rep. 2017;38(5):2787-95.

5. Amadori $D$, et al. A randomized phase II non-comparative study of pemetrexed-carboplatin and gemcitabine-vinorelbine in anthracyclineand taxane-pretreated advanced breast cancer patients. Int J Oncol. 2013;42(5):1778-85

6. Dittrich $\mathrm{C}$, et al. A phase II multicenter study of two different dosages of pemetrexed given in combination with cyclophosphamide as first-line treatment in patients with locally advanced or metastatic breast cancer. Cancer Invest. 2012;30(4):309-16.

7. O'Shaughnessy JA, et al. Phase II study of pemetrexed in patients pretreated with an anthracycline, a taxane, and capecitabine for advanced breast cancer. Clin Breast Cancer. 2005;6(2):143-9.

8. Martin M. Clinical experience with pemetrexed in breast cancer. Semin Oncol. 2006;33:15-8.

9. Park JH, et al. Exceptional pemetrexed sensitivity can predict therapeutic benefit from subsequent chemotherapy in metastatic nonsquamous non-small cell lung cancer. J Cancer Res Clin Oncol. 2019;145(7):1897-905.

10. Nambaru PK, et al. Drug efflux transporter multidrug resistanceassociated protein 5 affects sensitivity of pancreatic cancer cell lines to the nucleoside anticancer drug 5-fluorouracil. Drug Metab Dispos. 2011;39(1):132-9.

11. Pratt $S$, et al. The multidrug resistance protein 5 (ABCC5) confers resistance to 5-fluorouracil and transports its monophosphorylated metabolites. Mol Cancer Ther. 2005;4(5):855-63.

12. Janke $D$, et al. 6-mercaptopurine and 9-(2-phosphonyl-methoxyethyl) adenine (PMEA) transport altered by two missense mutations in the drug transporter gene ABCC4. Hum Mutat. 2008;29(5):659-69.

13. Alexa-Stratulat $T$, et al. What sustains the multidrug resistance phenotype beyond $A B C$ efflux transporters? Looking beyond the tip of the iceberg. Drug Resist Updat. 2019;46:100643.

14. O'Shaughnessy JA. Pemetrexed: an active new agent for breast cancer. Semin Oncol. 2002;29(6):57-62.

15. Wan F, et al. A systemic analysis on pemetrexed in treating patients with breast cancer. Asian Pac J Cancer Prev. 2014;15(11):4567-70.

16. Liu C, et al. Differential effects of thiopurine methyltransferase (TPMT) and multidrug resistance-associated protein gene 4 (MRP4) on mercaptopurine toxicity. Cancer Chemother Pharmacol. 2017;80(2):287-93. 
17. Robert NJ, et al. Results of a phase II study of pemetrexed as first-line chemotherapy in patients with advanced or metastatic breast cancer. Breast Cancer Res Treat. 2011;126(1):101-8.

18. Ma D, et al. Clinical effect of pemetrexed as the first-line treatment in Chinese patients with advanced anaplastic lymphoma kinase-positive non-small cell lung cancer. Thorac Cancer. 2016;7(4):452-8.

19. Tang F, Hartz A, Bauer B. Drug-resistant epilepsy: multiple hypotheses, few answers. Front Neurol. 2017;8:301.

20. Liu Y, et al. The effects of splicing variant of PXR PAR-2 on CYP3A4 and MDR1 mRNA expressions. Clin Chim Acta. 2009;403(1-2):142-4.

21. Pela M, et al. Optimization of peptides that target human thymidylate synthase to inhibit ovarian cancer cell growth. J Med Chem. 2014;57(4):1355-67.

22. Hanauske AR, et al. In vitro chemosensitivity of freshly explanted tumor cells to pemetrexed is correlated with target gene expression. Invest New Drugs. 2007;25(5):417-23.

23. Robey RW, et al. Revisiting the role of $A B C$ transporters in multidrugresistant cancer. Nat Rev Cancer. 2018;18(7):452-64

24. Masuda M, et al. Methotrexate is excreted into the bile by canalicular multispecific organic anion transporter in rats. Cancer Res. 1997;57(16):3506-10.

25. Genovese I, et al. Not only P-glycoprotein: Amplification of the ABCB1containing chromosome region 7q21 confers multidrug resistance upon cancer cells by coordinated overexpression of an assortment of resistance-related proteins. Drug Resist Updat. 2017;32:23-46.

26. Assaraf YG. The role of multidrug resistance efflux transporters in antifolate resistance and folate homeostasis. Drug Resist Updat. 2006;9(4-5):227-46.

27. Wielinga PR, et al. Thiopurine metabolism and identification of the thiopurine metabolites transported by MRP4 and MRP5 overexpressed in human embryonic kidney cells. Mol Pharmacol. 2002;62(6):1321-31.

28. Liu Y, et al. Association of ABCC2 -24C>T polymorphism with high-dose methotrexate plasma concentrations and toxicities in childhood acute lymphoblastic leukemia. PLoS ONE. 2014;9(1):e82681.

29. Vlaming ML, et al. Impact of abcc2 [multidrug resistance-associated protein (MRP) 2], abcc3 (MRP3), and abcg2 (breast cancer resistance protein) on the oral pharmacokinetics of methotrexate and its main metabolite 7-hydroxymethotrexate. Drug Metab Dispos. 2011;39(8):1338-44.

30. Wielinga $\mathrm{P}$, et al. The human multidrug resistance protein MRP5 transports folates and can mediate cellular resistance against antifolates. Cancer Res. 2005;65(10):4425-30.
31. Vandana M, Sahoo SK. Reduced folate carrier independent internalization of PEGylated pemetrexed: a potential nanomedicinal approach for breast cancer therapy. Mol Pharm. 2012;9(10):2828-43.

32. Slot AJ, Molinski SV, Cole SP. Mammalian multidrug-resistance proteins (MRPs). Essays Biochem. 2011;50(1):179-207.

33. Hegedus $C$, et al. Lipid regulation of the $A B C B 1$ and $A B C G 2$ multidrug transporters. Adv Cancer Res. 2015;125:97-137.

34. Milosevic $V$, et al. Wnt/IL-1 $\beta / I L-8$ autocrine circuitries control chemoresistance in mesothelioma initiating cells by inducing ABCB5. Int J Cancer. 2020;146(1):192-207

35. Yang $C$, et al. ABCA8-mediated efflux of taurocholic acid contributes to gemcitabine insensitivity in human pancreatic cancer via the S1PR2-ERK pathway. Cell Death Discov. 2021;7(1):1-12.

36. Hlaváč V, et al. Pharmacogenomics to predict tumor therapy response: a focus on ATP-binding cassette transporters and cytochromes P450. J Pers Med. 2020;10(3):108.

37. Kadioglu $\mathrm{O}$, et al. Effect of $\mathrm{ABC}$ transporter expression and mutational status on survival rates of cancer patients. Biomed Pharmacother. 2020;131:110718

38. Uemura T, et al. ABCC11/MRP8 confers pemetrexed resistance in lung cancer. Cancer Sci. 2010;101(11):2404-10.

39. Oguri T, et al. MRP7/ABCC10 expression is a predictive biomarker for the resistance to paclitaxel in non-small cell lung cancer. Mol Cancer Ther. 2008;7(5):1150-5.

40. Hou Y, et al. The FOXM1-ABCC5 axis contributes to paclitaxel resistance in nasopharyngeal carcinoma cells. Cell Death Dis. 2017;8(3):e2659.

41. Kathawala RJ, et al. The modulation of $A B C$ transporter-mediated multidrug resistance in cancer: a review of the past decade. Drug Resist Updat. 2015;18:1-17.

42. Park $\mathrm{S}$, et al. Gene expression profiling of ATP-binding cassette (ABC) transporters as a predictor of the pathologic response to neoadjuvant chemotherapy in breast cancer patients. Breast Cancer Res Treat. 2006;99(1):9-17.

\section{Publisher's Note}

Springer Nature remains neutral with regard to jurisdictional claims in published maps and institutional affiliations.
Ready to submit your research? Choose BMC and benefit from:

- fast, convenient online submission

- thorough peer review by experienced researchers in your field

- rapid publication on acceptance

- support for research data, including large and complex data types

- gold Open Access which fosters wider collaboration and increased citations

- maximum visibility for your research: over $100 \mathrm{M}$ website views per year

At BMC, research is always in progress.

Learn more biomedcentral.com/submissions 